Library Collections, Acquisitions, \& Technical Services, 2000, Volume 24, Issue 4, Pages 443-458.

ISSN: $1464-9055$

DOI: $10.1016 / \mathrm{S} 1464-9055(00) 00171-8$

http://www.sciencedirect.com/science/journal/14649055

http://www.sciencedirect.com/science/article/B6VSH-41V35RT-1/2/a5dfdebbfefa3a28205d89b44c369039

(C) 2000 Elsevier Science Inc. All rights reserved.

\title{
Making the connection between processing and access: do cataloging decisions affect user access?
}

\section{Ruey L. Rodman}

\begin{abstract}
One function of a call number is to organize the library collection to promote browsability either on the shelf or in an online catalog. This study, based on research done at the Ohio State University Libraries, examines the impact on library collection organization if call numbers are not changed to fit into the shelf list sequence. The browsability of items were tracked by assessing how many screens away titles appear from like items in the online public access catalog, if call numbers by a bibliographic utility were not changed. The study assesses whether not reviewing the call numbers affects patrons' ability to find the items.
\end{abstract}

\section{Introduction}

With the ever-increasing "information explosion," libraries face difficult decisions on purchasing, book processing, and space allocation. Libraries must seek ways to cut costs and increase efficiency. One area under continuous scrutiny is book cataloging. A study by Magda El-Sherbini and John Stalker entitled, "A Study of Cutter Number Adjustment at the Ohio State University Libraries," is one example of research on this time-consuming process. Their study examines "existing copy cataloging procedures to assess whether it was feasible to eliminate the review and adjustment of cutter numbers in producing copy cataloging records. A change in this procedure might reduce processing costs and improve productivity" [1].

As a public service librarian at the Ohio State University (OSU) Libraries, this author questioned whether a change of this type would affect the accessibility of materials. More specifically, this author wondered if the non-adjustment of cutter number or non-adherence to strict alphabetic order would affect the "browsability" of materials in an online public access catalog (OPAC). The study takes the research of El-Sherbini and Stalker one step further. It compares the shelf-listed call number with the non-shelf-listed call number provided on a catalog record, and then attempts to assess the effect on the display of the title in an OPAC. 


\subsection{Scope and definitions}

Available cataloging copy in bibliographic utilities such as the OCLC, Inc. (OCLC) or the Research Libraries Information Network (RLIN) has done much to increase the speed of processing a book, but processing units still look for ways to increase efficiency and production. Also, services such as PromptCat, developed by OCLC, or shelf-ready materials provided by vendors, support library processing units in their efforts to receive an item and get it to the shelf as quickly as possible. Can libraries accept the copy of the record provided by a bibliographic utility without reviewing the content of the record? This study examines one part of the record, the call number.

Classifying and cuttering, or the assignment of call numbers, is a primary activity in cataloging. In general, bibliographic classification is designed to organize materials in a chosen way. A call number is designed in parts using established symbols, including a class number (representing subject), one or two cutters (representing geographic, topical, or specific author), and book number (representing alphabetic scheme). Call number assignment is the most prominent method used in libraries to organize collections systematically according to the subject matter of each item. The call number file is called the shelf list because it is arranged in the order the items are found on the shelf. This file promotes browsability among items that are grouped together by subject through call number assignment.

Classifying materials to permit effective browsing became more crucial with the rise of open access to materials by library patrons. As Osborn relates, "The provision of self-service on the part of readers grew out of conditions that were encountered for the first time in history in the 1820 's when in the British Museum some 200 readers a day presented requests for materials and subjects which were beyond the capacity of the librarian-as-a-living-catalog to fill, for example a request to see all of the library's holdings of materials printed in France during the French Revolution or a request for information on new discoveries around the world or new developments in all fields of science" [2].

For the purpose of this study the following definitions will be used.

1. Class number: a system of alphas and numerics used to keep like items together by subject whether on the shelf, in a card catalog, or in an OPAC display. Part of the class number may be a cutter for subject, topic, or specific author

2. Class number change: an adjustment made to the cutter

3. Book number: the alpha and numerics used to order items by author or title within a class number

4. Shelf listing: the process of adjusting the book number to fit an item into an existing sequence of materials

Throughout the study these definitions are used to differentiate between subject organization (class number portion) and alphabetic organization (book number portion). The phrases "shelf listing" and "call number assignment" both refer to the act of adjusting the book number.

By eliminating shelf listing, the role of the call number functions more as a shelf position indicator and less as a means of keeping like items together. In many libraries the bar code, rather than the call number, is the unique number assigned to each item. With the use of bar codes it may no longer be critical to assign a unique call number to each item. Therefore, 
duplication of call numbers will be tracked as a possible factor that might have an impact on the library collection.

\subsection{Literature survey}

A review of the literature did not reveal any research addressing the impact on call number display in an OPAC if shelf listing is eliminated in the cataloging process. Besides the El-Sherbini and Stalker article, Massey and Malinconico have also contributed research on cutting processing costs by accepting call numbers from records provided by a bibliographic utility. Massey and Malinconico reach a similar conclusion to El-Sherbini and Stalker: "the results of this study indicate that local shelf listing is not a cost-effective operation for the University of Alabama libraries . . . The small number of errors detected produced a small amount of shelflist disorder and would, therefore, be expected to have a low impact on the browsability of the collections" [3]. The University of Alabama Libraries is no longer shelf listing call numbers on provided copy. Many years ago at the OSU Libraries, shelf listing was suspended in all classes with the exception of classes $\mathrm{M}, \mathrm{N}$, and $\mathrm{P}$. These exceptions were made in order to maintain the established single cutter for musicians, artists, and literary authors.

This author examined other research areas that might influence a library to consider eliminating shelf listing as a part of book processing. The research can be categorized into three broad areas: 1) classification schemes in an online environment, 2) the quality of bibliographic records in the online databases of bibliographic utilities, and 3) catalog use studies and/or information seeking behavior studies.

\subsection{Classification schemes in an online environment}

There are many studies that discuss the use of classification schemes as a means of improving access to items in an online environment. Most of these reports concern the enhancement of classification schemes through direct linking of class number to subject index files. Broadbent [4] highlights the issues by exploring whether an online catalog can function both as a dictionary and classified catalog without requiring additional time or intellectual effort on the part of the cataloger. Drabenstott [5] discusses the importance of incorporating a classification scheme into the retrieval protocols of an online catalog, to introduce a logical approach to subject searching and to increase the amount of information in subject indexes from the subjects in bibliographic records.

There is also research being done on multiple class number assignments in bibliographic records in an online environment. Huestis [6] describes the development of clusters of classification numbers in an index, that are associated with bibliographic records and accessible in the online index-searching program. Past and present classification practices are summarized by Hill [7] who proposes that catalogers provide enhanced subject access through multiple classification numbers. Losee [8] examines the clustering of similar books provided by a classification system. He examines the relationship between the relative shelf location of a book and the books that users choose to circulate to impact the design of classification and clustering systems supporting browsing in online public access catalogs and in full-text electronic storage and retrieval systems. 
Classification schemes being used as independent online retrieval tools are also of interest. Cochrane and Markey [9] present research on data elements that have been enumerated for the purpose of constructing files of library classification records to assist in information retrieval. Williamson [10] addresses innovations in thesaurus design and standards to examine how classification structure will support information retrieval. Both of these articles conclude that an online classification index can aid in retrieval, although research into its design, users, and expected results still needs to be addressed.

The above research implies that current classification practices alone are not an effective tool for the retrieval of information, or are not used to the fullest advantage. In a 1986 survey of ARL libraries, seventy-seven libraries (77) were still maintaining a card shelf list file [11]. The reasons for doing this were that a true shelf list function was not available online, that parts of the collection needed retrospective conversion, and that better browsability functions were needed in online systems. As Chan states, "Classification holds great promise for augmenting effectiveness in online retrieval. While certain characteristics of classification prevent its being a totally reliable retrieval tool by itself, it can be a useful supplementary device" [12]. Gertrude Koh [13] supports Chan's statement in her research on a "subject tool box" or a combined system of subject headings and classification which will meet user learning styles and vocabulary and assist in online "shelf browsing." By itself, classification may not be an effective retrieval protocol, but in combination with other search mechanisms it provides added value for user searching. However, non-adjustment of call numbers can be viewed as a possible development in the use of classification in online systems. If many libraries use standard call numbers provided on records in a bibliographic utility, the development of classification schemes and their uses as search tools may become more acceptable. The results may be applied to many libraries rather than one library at a time.

\subsection{Quality of records in bibliographic utilities}

The second area of research examined for this study concerns the accuracy of copy provided by bibliographic utilities. These studies include all fields in the provided record, of which the call number is but one element. In 1987 at the Mann Library of Cornell University, Janet McCue and others found that in an analysis of cataloging copy from the RLIN database, $57.44 \%$ of a total of 85.3 changes were modifications to the classification number. The authors state, "The fact that one or more Mann catalogers changed the classification on 39 of 80 records (including $4 \mathrm{~L}$ [ibrary of] C[ongress records]) illustrates the latitude possible in determining classification" [14]. The authors do not define their use of the term classification, but one gets a sense from the content of the article that the term is applied to the class number portion of the call number. They recommend more in-depth training on choice and form of classification numbers by copy catalogers.

Shared cataloging as accepted or applied by local libraries is of great interest to the library community. In a study on the accuracy of LC copy, Arlene Taylor and Charles Simpson [15] also included classification as an access point worth consideration in their research. They found that there were $4.3 \%$ problems with call numbers in the Cataloging in Publication (CIP) sample and 5.5\% problems with call numbers in the non-CIP sample in their study. The article does not present data on the types of problems found in the classification, but the problems are considered significant because classification is seen as a major access point. 
There seems to be a general perception that classifying a document or assigning just the class number portion is a very individualized process. Thus, one classifier's subject analysis and classification assignment might be different from another classifier's for the same item. The inconsistencies of classification through subject analysis do point to another possible weakness in the sharing of call numbers without adjustment. Does class number assignment have an impact on a decision to accept call numbers without review? In an investigation of information retrieval from a classification of words used to group documents together, Jones states, "By this [a certain sort of classification] I mean a classification in which members of a class do not necessarily all share one or more common properties, and in which individual items can appear in more than one class... . This is a natural consequence of the fact that the documents in a collection, though they may be topically related, are not likely to be identical in both subject matter and vocabulary" [16]. Jones further discusses the difficulty in accurately and consistently assigning the correct identifier to similar documents in order to group them together for retrieval. Consistency in the use of any classification scheme seems to be somewhat problematic. Bibliographic classification differences in libraries may also be affected by the needs and expectations of each library. Current practice assigns one class number to an item based on the first subject heading. If classification is a subjective decision-making process, can we then assume that the general class indication of content or topic is acceptable, or that the call number is relegated to be just a shelf position indicator?

There are surveys administered by bibliographic utilities to assess users' perceptions about record quality in their databases. In an article about a survey of records in the OCLC database, Davis [17] asks two questions concerning the seriousness of errors, and the perceptions of how well existing programs addressed quality control needs. The research interest in shared records by both user and provider is important because this study investigates the acceptance of a provided field without review.

\subsection{Catalog use studies}

The last research area examined for this study is catalog use studies and information seeking behaviors. In these areas there is a wealth of research. The following from R. Hyman's introduction in his Access to Library Collections sums up the issues involved.

"An investigation of any aspect of the direct shelf approach involves one immediately in a central problem which ramifies [i.e., divides], often unexpectedly, into almost every major concern, theoretical and practical, of librarianship. Thus, one may easily become entangled in: selection and acquisition policy ... ; the function of cataloging, particularly of subject heading, vis-à-vis classification; general versus special classification schemes; documentation as related to librarianship; the utility of mnemonic and of expressive notation; bibliothecal as against bibliographical classification; the differing interpretations of the browsing concept (and of browsability) for research and for non-scholarly library use; how to determine and store lessused or obsolescent materials; the divergent philosophies on the desirable extent of readers' services and reference assistance; the worth and form of independent study in the library; the suitability of the LC Classification (LC) or of the Dewey Decimal Classification (DC) for various types and sizes of libraries-an issue often complicated by concomitant problems of reclassification; the encroachments on direct access resulting from increased use of microforms and from possible mechanized information storage and retrieval; the proper educational, social, 
or scholarly functions of libraries. Nor is this by any means a full listing of the threatening entanglements" [18].

Even though this statement was written in 1972, it seems to hold true today. When studying the organizational structure of the library's collection, or the direct shelf approach, all of the library's parts or activities come under scrutiny. Use of card files or online files is usually the initial contact by a patron when beginning to seek materials on a subject or to look for a specific item. Making a change in just one of the available files could affect many aspects of how a library is organized and operates.

Catalog use studies investigate not only how information is organized and retrieved, but also the schemes used to organize the information in the physical arrangement of the library as well as in online systems and their retrieval capabilities. A common conclusion reached in many reports is that when seeking information, users do not use the call number file as their initial search option. For the most part, users approach the search for information from a known item point of view (author or title search) or from a subject perspective [19-21]. After completing the search, they use call numbers to locate the item on the shelf. Patrons will then browse nearby items for other appropriate titles. They use call numbers as pointers to the physical item, and when they find the shelf area in the library they browse titles, not call numbers.

Although the following statement by Thomas Mann is not from a user study, it does summarize another aspect of patron behavior that influences search strategies. Mann's Principle of Least Effort "states that most researchers (even 'serious' scholars) will tend to choose easily available information sources, even when they are objectively of low quality, and further, will tend to be satisfied with whatever can be found easily in preference to pursuing high-quality sources whose use would require a greater expenditure of effort" [22]. In general, users want their information search to be quick, easy, usable, and limited in number of items retrieved.

Another common thread in user study reports is the classification scheme itself and how it is manifested in the physical arrangement of items in the library. The classification of the store of human knowledge is indeed a very complex issue. As stated by Langridge, "In the bibliographic context, 'classification' is commonly taken to imply 'classification schemes'. These represent the fullest use of classificatory methods, but the term 'classification' by itself really means a way of thinking that pervades all subject work" [23].

A "way of thinking" is the crux of the issue facing libraries today. Each and every user may have his or her own way of approaching a search for information. It is difficult to assess how an "average user" thinks in order to design the best scheme for organization. The LC Classification schedules are very complex, and without some explanation, patrons may not be able to use them. The full call number is used by patrons to locate the item on the shelf, and only in its broadest sense (class number only) will "classification" assist the patron in browsing by linking like items together. There is much activity, study, and discussion in the area of classification research. Classification schemes or call number assignments are revised to meet the continuing changes in information, are examined in records found in bibliographic utilities, and are studied to determine their use by those searching for information. This study may raise more questions than it answers, but it is hoped that the research will shed some light on the nonadjustment of call numbers as a viable option for librarians to consider. 


\subsection{Research objectives and methodology}

From home, office, or in the library, the online catalog serves as the initial point for users to begin their search for information. The research questions examined by this study are: Is it necessary to adjust the book number to maintain alphabetic order of items within a class? If not, how does this affect the call number display in an OPAC? In other words, to what degree will the browsability of a collection in an online catalog change if call numbers are not shelf listed? The preponderance of literature describes the need for research and development in the use and application of classification systems and the need for more analysis of searching behaviors. No research has been done to show whether or not the suspension of concatenation or linking in a series affects the browsability for information in an OPAC. Libraries might be able to abandon strict alphabetic order for speedier, more efficient processing of materials if browsability in the call number file is not greatly affected.

Data are collected on the call numbers in the bibliographic record. Data are also collected on the edited or shelf listed call number to compare with the original call number provided by a bibliographic utility. The impact on the browsability of an item or the effect on the display of the title in an OPAC is then assessed. The initial results will also be examined over three years to track any change in OPAC display position of the titles.

The data for this study was taken from items copy cataloged during three months in 1992 at the OSU Libraries, which uses LC Classification. Data have been compiled on books that received copy cataloging using bibliographic records found in the OCLC Union Catalog. These bibliographic records were considered acceptable if they included a LC Classification number and subject entries. Records that did not have a LC call number were eliminated from the sample. Because this study is primarily concerned with the effect of shelf listing in the OPAC display of titles, no attempt has been made to ascertain the correctness of the class assignment, and it is assumed that the class number on the bibliographic record as found in OCLC was valid.

In order to provide a description of the overall sample as found in OCLC, the following data elements were tracked from the supplied copy:

1. cataloging input agency: LC or member institution

2. the encoding level: blank (LC), I (member institution), 8 (CIP cataloging), and other (e.g., 5 for minimal level cataloging)

3. bibliographic description: blank (non-ISBN), a (AACR2), I (ISBD form)

4. call number field tag: 050 (assigned by the LC), 090 (assigned by member institutions using the LC Classification scheme)

An analysis of the portions of the call numbers that were changed was also done to identify the types of changes made to the call number for shelf listing purposes. The categories used to track the call number changes were:

1. classification (includes topical, geographic, or author cutter)

2. book number (cutter used to alphabetize into the shelf list)

3. changes required for local practice (adding a date, adding a number one for English translation, etc.)

4. no change required

In addition to the above, it was noted whether an unchanged call number matches or duplicates a call number already in the call number file. It was also noted if the changed call 
number was literature or LC Classification P.

In summary, to assess the browsability of like items in the OPAC, three basic steps were used to analyze the sample: 1) a description of the type of copy used in book processing, 2) call number analysis to assess how many call numbers were changed, and 3) of the call numbers that were changed, how many would have been one, two, or three or more screens away if not changed. The last step could only be done after step two, which eliminates those items in which the call number has not been changed.

Approximately 250-300 cataloged items in all formats were cataloged daily at the OSU Libraries. Every tenth title was selected for the sample as representative of the approximately 12,000 to 15,000 items normally added to the collection every three months. The sample was selected according to the following conditions:

1. Only those items that were copy cataloged were used. Any items that were "originally cataloged" at the library were removed during the analysis of the overall sample

2. Only monographs (including microforms) were used as source data

3. Those items cataloged with a locally constructed call number (not LC classification) were eliminated

The source data used in this study were three years old when analysis began. Approximately 200,000-225,000 items have been added to the online catalog since the sample items were cataloged. By counting lines in the online catalog display for the unedited call numbers, an estimate of the effect of browsability in the OPAC was based on a period of three years.

The sample yielded a total of 1,130 titles. The analysis began with a brief description of the type of copy provided. The fields chosen to describe the sample were the cataloging source field, the encoding level field, the description field, and the call number field tag. The definitions for these fields were taken from the document Bibliographic Formats and Standards (1993, FF:3-75. 079-83) issued by the OCLC Online Computer Center, Inc. In all cases the first part, or subfield "a," of the 040 field was used to identify the original source of the cataloging data. The LC supplied 753 titles (66.6\%) and OCLC member institutions supplied 377 titles (33.4\%).

The encoding level field was examined next. Encoding level indicates the degree of completeness of the machine-readable record. The LC, National Library of Medicine, British Library, National Library of Canada, National Library of Australia, and the National Series Data Program use blank and numeric codes in this field. Member institutions use capital letter codes. Encoding level "blank" is defined as full-level cataloging; encoding level 8 is the code for prepublication-level cataloging or the Cataloging-in-Publication program (CIP). Encoding level I indicates full-level cataloging input by OCLC member institutions. These codes were examined because they are indicative of full-level cataloging which should include a complete call number. Other codes used in the field, e.g., 5 or M, usually indicate less than full-level cataloging. Less than full cataloging codes are grouped together into a category titled "other." The results for the encoding level field are blank $=511$ titles $(45.2 \%) ; \mathrm{I}=337$ titles $(29.8 \%) ; 8=243$ titles $(21.5 \%)$; and other $=39(3.4 \%)$.

The description field indicates whether the item has been cataloged according to the provisions of the International Standard Bibliographic Description (ISBD). The three possible indicators for this field are: "blank," which indicates that the record is in non-ISBD form; "a," which indicates that the record is in AACR2 form (Anglo-American Cataloging Rules, second edition); and "I," which indicates record is in ISBD form and is known to be a non-AACR2 record. The description codes are concerned with the bibliographic description of the record's 
content, and do not imply whether the choice and form of the headings used in the record follow AACR2 standards and rules. The results were level $\mathrm{a}=1,064$ titles $(94.2 \%)$; level blank $=38$ titles $(3.4 \%)$; and level $\mathrm{I}=28$ titles $(2.5 \%)$.

Based on these three data elements (cataloging source, encoding level, and description), $66.6 \%$ of the copy used was provided by national libraries, and $75.0 \%$ was full-level cataloging. One-third of the sample or $33.4 \%$ was input by member institutions of which $29.8 \%$ was input at full-level cataloging. Overall, $94.2 \%$ of the sample used in this study was input in AACR2 form. Only $3.4 \%$ is in less than full cataloging, and $5.9 \%$ of the records were in earlier forms of bibliographic description. To summarize, $96.5 \%$ of the sample (encoding levels blank, I and 8) and $94.2 \%$ of the sample (description a) indicated usable, full-level available copy.

Call number assignment field tag was the next element examined. Acceptable copy at OSU Libraries is defined as having a LC call number or field tags 050 or 090. When neither of these tags were present, the record was also tracked and defined with other tags, e.g., 060, 070, 082, 092 that are not used by the OSU libraries for cataloging. The field tag 050 is defined as a call number assigned by the LC, and the 090 field tag is defined as a call number based on the LC Classification schedules but assigned by an OCLC member institution. The results were that 1,065 titles (94.2\%) had 050 and 090 tags, and 65 titles $(5.8 \%)$ had other or no tags. The 65 titles in the "other or not present" category were eliminated from further analysis because this type of call number is always shelf listed and would not have been accepted without review. With the elimination of the 65 titles, the sample size was reduced to 1,065 .

Another book processing requirement of the OSU Libraries is that the selected copy must have valid LC subject headings (650 field tag). This category does not affect the study except that items without valid subject entries would be forwarded to the original cataloging section. This category was counted to determine how many items would have been removed from processing without review. Of the 93 titles without subject entries, 67 titles were classed as literature, which do not require subject analysis. Only 26 titles had no subject entries. None of these titles were eliminated from the sample at this point because they were processed using the call number found on the copy, although these all required expert attention to other fields before cataloging was complete.

The last category used in this study to define the sample answers the question: Does a record have original cataloging input by the OSU Libraries? This question is important because it means that no bibliographic record was available in OCLC. A cataloger at the OSU Libraries would catalog the item, including a shelf listed call number, before input to the OCLC Union Catalog. This study examined those items that were copy cataloged using a bibliographic record already in OCLC. Forty-five titles were found to be originally cataloged by the OSU Libraries.

To summarize, the initial sample was reduced by 65 titles that did not have a call number and by 45 more titles that were originally cataloged. The total sample size was now 1,020 titles. Of these, only the call number was examined further. The initial examination determined whether the call number on the bibliographic record was changed or whether it was accepted as found in the bibliographic record. Seven hundred ninety six titles $(78.0 \%)$ contained call numbers originally provided on the bibliographic record which were accepted without revision during the copy cataloging process. The sample size for further call number analysis was therefore reduced to 224 titles. 


\subsection{Results}

Of these 224 titles, three categories were tracked to identify which part of the call number was changed. First, it was noted if the class number, which includes author, geographical, or topical cutter, had been changed. This change was counted first and as the only change even if other parts of that call number were changed. Second, the book number, which alphabetizes the title into the collection, was examined. This category was counted as the only change if it was the only element changed in the call number. Third, changes due to local practice were counted as the one and only change provided that the class and book numbers were not changed. There were three local practices included in this study: 1 ) adding a number one to the book number to indicate English translation; 2) adding a cutter, Z8, to show literary criticism; and 3) adding a year to the call number. The results of the analysis of the parts of the changed call number can be seen in Table 1.

\section{Table 1}

\section{Call number changes}

\begin{tabular}{lrc}
\hline $\begin{array}{l}\text { Changes to } \\
\text { Call Number }\end{array}$ & Titles & $\begin{array}{l}\text { Percent of } \\
\text { Sample }\end{array}$ \\
\hline Class Number & 71 & $31.7 \%$ \\
Book Number & 120 & $53.6 \%$ \\
Local Practice & & \\
$\quad$ Translation & 12 & $5.4 \%$ \\
Z8 Cutter & 4 & $1.8 \%$ \\
$\quad$ Year & 17 & $7.6 \%$ \\
Totals & 224 & $100.1 \%{ }^{*}$ \\
\hline
\end{tabular}

*Percent is more than 100 due to rounding

By checking where the record would file if the call number had not been edited and comparing it to where the record would file with an edited call number, the "browsability," or how close together on the screen the two call numbers are, can be estimated. The OPAC display of call number in OSU's Innovative Interfaces' system displays eight call numbers on one screen. When a call number is input that does not match an existing call number, the input call number is displayed in the middle of the screen with four call numbers above and below. For this study, the call number lines are translated into OPAC screen displays as follows:

1-4 lines are equal to the same screen;

5-12 lines are equal to one screen away;

13-20 lines are equal to two screens away;

21-28 lines are equal to three screens away;

$29+$ are equal to more than four screens away;

The results of the OPAC search on the unchanged call numbers in relation to the shelf listed call numbers appear in Table 2. 
Note that 187 items $(83.5 \%)$, that were within twelve lines of the call number, would probably have been found or seen by the patron if they follow Mann's Principle of Least Effort. In essence, the change to the call number was relatively slight when position in the OPAC display was examined. This does leave 37 (16.6\%) of the titles that are two or more screens away. If a user was following the principle, this would result in a missed or failed search result.

\section{Table 2}

\section{OPAC display result for provided call number}

\begin{tabular}{lcc}
\hline Number of Screens & Titles & $\begin{array}{l}\text { Percent of } \\
\text { Sample }\end{array}$ \\
\hline Same Screen & 136 & $60.7 \%$ \\
One Screen Away & 51 & $22.8 \%$ \\
Two Screens Away & 13 & $5.8 \%$ \\
Three Screens Away & 2 & $1.0 \%$ \\
Four+ Screens & 22 & $9.8 \%$ \\
Away & 224 & $100.1 \% *$ \\
Totals &
\end{tabular}

In the OSU Libraries' OPAC system, the call number does not have to be unique when a record is added to the database. The unique number for each item is the barcode. It is technically possible to have two different items with the same call number and still retrieve them for circulation purposes. It is not known whether this would be confusing to patrons when seen in the OPAC display or on the shelf. Thus, an additional category was tracked to determine the percentage of duplicated call numbers if a call number was accepted without review. It was also noted whether the titles were different or the same.

Of the 224 titles, eight (3.6\%) duplicated an existing call number. In six of the eight titles $(75 \%)$ the titles were different, which means that the same call number was assigned to two different items. Of the two unchanged call numbers $(25 \%)$, one matched a call number input to this OPAC by another library. The other unchanged call number represented the second edition of a title that matched the call number used for the cataloged first edition.

Since approximately $25 \%$ of this collection is in the literature classifications, two additional categories of information about the changed call numbers were tracked:

1. whether the item is literature, and

2. whether the call number change was made to keep literary authors together

Of the 71 changes made to class number, 55 (77.5\%) were classed in literature. If these adjustments had not been made to the call numbers, a "new" class number sequence would have been established for these authors. Therefore, the works of these authors would have been found in two shelf locations. The remaining 16 titles $(22.5 \%)$ were not literature. Upon review of these titles, the author determined that the class number portion was changed because of a topical or geographical cutter. These changes were made to keep the same topics or geographical areas together in the same shelf location. 
After the compilation of the results of the first search in December 1995, the author intended to do a time series projection based on the results and to check the OPAC displays two more times. However, when the OPAC displays were examined in March 1997 and May 1998, no change had occurred in the display positions of the 224 titles. Either the size of the collection did not increase enough or collecting in the subject areas of the 224 titles was not significant enough to make any change in the OPAC display position. Another possibility is that, since 1995, the unchanged call numbers would have compounded the out-of-sequence items. This aspect of the OPAC display results has not been tracked or factored into the results of this investigation.

\section{Summary}

Since the size of the library collection seems to have an effect on the OPAC displays, some overall projections might be made for one year of production against the size of the database. Of the original sample, 224 titles $(21.9 \%)$ had a call number change. If these call numbers had not been changed then 224 titles would not be in correct order in the OPAC display. However, $187(83.5 \%)$ of the 224 titles appear on the same screen or one screen away and are considered easy to find if a search of the OPAC is done by call number. The remaining 37 titles $(16.6 \%)$ would fall two or more screens away and are considered not easy to find. Note that 796 titles $(78 \%)$ of the sample titles would fit perfectly into the collection without call number adjustment.

Based on these results, the following projections can be made for one year of production. There are approximately 45,200 monograph titles added to OSU's collection in one year. Of these titles, 43,256 (90.2\%) could be processed because there was available, acceptable copy. There would be approximately 9,473 (21.9\%) call number changes. If these call numbers had not been changed, these titles would then be out of order in the OPAC display. However, of the unchanged call numbers, 7,909 (83.5\%) titles would be on the same screen or one screen away from the shelf listed call number. This leaves 1,572 (16.6\%) titles with unchanged call numbers that would be two or more screens away.

The first OPAC search was done in 1995, three years after the sample titles had been processed. The estimated size of the database at that time was 2,865,000 titles. Following the line of reasoning above, after three years of production, there would be 4,716 titles $(0.16 \%)$ of the entire database) out of sequence by more than two screens in the OPAC display. Using $0.16 \%$ as the percentage for out-of-sequence titles against yearly database growth, predictions can be made on the number of titles in the database that would be more than two screens away from a shelf listed call number. The above results do not take into account any compounding that may occur because of the out-of-sequence items. This study has not examined whether compounding is a significant factor in increasing the number of items out-of-sequence over time.

The literature titles are more of a problem if titles are out-of-sequence. With literature, it is the class number that becomes the key element in accepting call numbers without review. Only a cursory review of literature titles was done in this investigation. There were 55 (24.6\%) literature titles with changed call numbers of the 224 titles that were searched in the OPAC. Of these fifty-five titles, $53(93.4 \%)$ had a change made to the author cutter, which is the element used to keep the works of an author together on the shelf. Without this call number adjustment, the works of an author would be shelved in two or more locations. This investigation did not 
review the literature titles further, but it would be interesting to note how far from the established class number an unchanged literature call number would fall, not only in the OPAC, but also on the shelf.

\section{Conclusions}

The research question asked in this study is: To what degree will the browsability of a collection in an OPAC change if call numbers are not shelf listed? The results indicate that for this library's collection, after three years, $0.16 \%$ of total titles cataloged without call number review may not be easily found in the OPAC. This is not a large percentage, and therefore nonreview of call numbers in cataloging would seem to be an acceptable decision for cutting costs and increasing productivity.

There are serious questions raised by this study that have not been answered, and more research is recommended. This research was limited to a call number search and the display results of titles in an OPAC. The decision on what would be "findable" was based on readings about user retrieval preferences. Patrons do not like to retrieve too many titles for review. Also, patrons prefer a known item approach or subject approach, and so it is assumed that all titles would be retrieved by this type of search protocol, no matter what the call number assignment.

An important constraint of this research is that the OPAC results were not translated to the actual shelf position in the library. This decision was based on the assumption that in this digital age, the user will search online and then use the call number to find the item on the shelf. Accepting call numbers without review may have one result in the OPAC display and an entirely different result when the actual shelf position of the item is examined.

Assume that a user selects an item from a search of the OPAC. The patron jots down the call number and goes to the shelf to retrieve the item. The item selected is one that had a call number that was not changed during processing and is found five shelf ranges away from like items in the collection. Would the patron be satisfied with this result? Would the patron realize that more items exist but are not shelved in close proximity to the selected title? How does screen display position translate to actual shelf position? How are the items actually shelved in each library? In this OPAC, the call number sequence display is continuous no matter what the format or material type. If a library shelves formats separately, e.g., monographs in one area and serials in another, a shelf position examination might have very different results.

By accepting call numbers as found on copy without review, how many classification sequences would actually be established for a given topic? It has been established in the review of available copy that $66.6 \%$ of records used were provided by the LC and $33.4 \%$ were provided by member institutions. If a call number input by the LC for a topic has a cutter of R66 and is accepted without review and the library had already established this topic as R6, the result is that two sequences have been established for one topic. It is assumed that the LC class assignment will remain consistent. If member institution call numbers are accepted without review for the same topic, yet another cutter might be established. A library collection could contain quite a few class sequences for items that are traditionally classed together. This could be a problem, not only in the browsing of the OPAC, but also in the browsing of the shelves.

This leads one to question the extent to which a library's processing/maintenance policy extends to the re-cataloging of items to keep them together. Classification schemes by their very nature are under constant revision to codify new information, new research areas, or change 
already established class number notations. Do libraries go back and adjust class numbers of items if a change has been made to the scheme? It is assumed that they do not because of limited resources. If they do not re-catalog because of schematic changes, would it be necessary to recatalog items that are out of order because of processing choices?

The above brief discussion does not include all of the issues associated with this study. However, the study shows that from the sample group approximately $78 \%$ of the copy cataloged items fit into this library's collection without needing any call number adjustment. It showed that $21.9 \%$ of processed items required a call number adjustment which was so slight that the unchanged call number was on the same screen or the next screen in the OPAC display. This leaves $16.6 \%$ of the items out of sequence by two or more screens, which when factored into the entire collection results in $0.16 \%$ total titles not easily found in the OPAC.

When taken by themselves, the statistics seem to make the proposition of processing items without call number review somewhat attractive. However, when translated to the collection's physical arrangement it may become less attractive. This author proposes that size of the library collection does make a difference. A similar study on a small library collection would make an interesting comparison.

In the virtual world, should the core method of systematic classification that organizes our collections be suspended? As LeBlanc states, "Will the access potential of the virtual library prove healthily cornucopian, or will the browsability of this new informational format permit the retrieval of only so much fodder from the cybernetic trough - enough to sustain users, but not enough to satisfy them" [24]? The authors hopes that this examination of call number assignment and how it might be applied or not applied in processing provides some new ideas or insights.

\section{References}

[1] El-Sherbini M, Stalker JC. A study of cutter number adjustments at the Ohio State University Libraries. Library Resources \& Technical Services, 40 (October 1996):320.

[2] Osborn AD. From Cutter and Dewey to Mortimer Taube and beyond: a complete century of change in cataloguing and classification, Cataloging \& Classification Quarterly 12 (1991):36.

[3] Massey SA, Malinconico SM. Cutting cataloging costs: accepting LC classification call numbers from OCLC cataloging copy, Library Resources \& Technical Services, 41 (January 1997):38.

[4] Broadbent E. The Online Catalog: Dictionary, Classified, or Both? Cataloging \& Classification Quarterly 12 (1991): 108.

[5] Drabenstott KM, et al. Analysis of a bibliographic database enhanced with a library classification, Library Resources \& Technical Services, 34 (April 1990): 179.

[6] Hill JS. Online classification number access: some practical considerations, The Journal of Academic Librarianship, 10 (March 1984):21.

[7] Huestis JC. Clustering LC classification numbers in an online catalog for improved browsability, Information Technology and Libraries, 7 (December 1988):383.

[8] Losee RM. The relative shelf location of circulated books: a study of classification, users, and browsing, Library Resources \& Technical Services, 37 (April 1993):197-8.

[9] Cochrane PA, Markey K. Preparing for the use of classification in online cataloging systems and in online catalogs, Information Technology and Libraries, 4 (June 1985):108 -9.

[10] Williamson NJ. The role of classification in online systems, Cataloging \& Classification Quarterly, 10 (1989):99.

[11] Epple M, Ginder B. Online catalogs and shelflist files: a survey of ARL Libraries, Information Technology and Libraries, 6 (December 1987):294.

[12] Chan LM. Library of Congress class numbers in online catalog searching, RQ 28 (Summer 1989):536.

[13] Koh GS. Options in classification available through modern technology, Cataloging \& Classification 
Quarterly, 19 (1995):196.

[14] McCue J, Weiss PJ, Wilson M. An analysis of cataloging copy: Library of Congress vs. selected RLIN Members, Library Resources \& Technical Services, 35 (1991):73.

[15] Taylor AG, Simpson CW. Accuracy of LC copy: a comparison between copy that began as CIP and other LC cataloging, Library Resources \& Technical Services, 30 (October/December 1986):377.

[16] Jones KS. Some thoughts on classification for retrieval, Journal of Documentation, 26 (June 1970):91.

[17] Davis CC. Results of a survey on record quality in the OCLC database, Technical Services Quarterly, 7 (1989):44.

[18] Hyman RJ. Access to library collections: an inquiry into the validity of the direct shelf approach, with special reference to browsing, Metuchen, NJ: Scarecrow Press. 1972, p. 2.

[19] Wallace PM. How do patrons search the online catalog when no one's looking? Transaction log analysis and implications for bibliographic instruction and system design, RQ, 33 (1993):239.

[20] Tagliacozzo R, Rosenberg L, Kochen M. Access and recognition: from user's data to catalog entries, Journal of Documentation, 26 (September 1970):248.

[21] Hancock M. Subject searching behavior at the library catalog and at the shelves: implications for online interactive catalogues, Journal of Documentation, 43 (December 1987):306.

[22] Mann T. Library Research Models: a Guide to Classification, Cataloging, and Computers. New York: Oxford, 1993, p. 91.

[23] Langridge DW. Classification: Its Kinds, Elements, Systems, and Applications. London: Bowker-Sauer. 1992.

[24] LeBlanc J. Classification and shelflisting as value added: some remarks on the relative worth and price of predictability, serendipity, and depth of access, Library Resources \& Technical Services, 39 (July 1995):302. 